\title{
Correlation Between Forearm Positions Across Elbow Joint and Ulnar Nerve Conduction Velocity Among Mobile Hand-Held Users
}

\author{
Doaa H.Mahmoud ${ }^{1}$, Prof. Dr. Amir M. Saleh², Dr. Magda R. Zahran ${ }^{3}$ \\ ${ }^{1}$ BSc of Physical Therapy, Department of Basic Science, Cairo University. \\ ${ }^{2}$ Professor of Physical Therapy, Faculty of Physical Therapy, Cairo University. \\ ${ }^{3}$ Lecturer of Physical Therapy, Faculty of Physical Therapy, Cairo University.
}

*Correspondence to

Doaa H. Mahmoud

Department of Basic science, Faculty

of physical therapy, Cairo university,

Egypt.

Tel:01000698323

Email;doaa.hamdy.hd@gmail.com

Published online:

June-2020

\begin{abstract}
Background: Mobile hand-held devices usage are on the rise in everybody's life that can be associated with physical health related problems, such as pain and numbness in the elbow and wrist and exposes forearm and hand to intense stresses at certain positions that may lead to peripheral nerve disorders.

Purpose: To study correlation between forearm positions across elbow joint and ulnar nerve conduction velocity among mobile-hand held devices users.

Design of the study: One shot case study.

Subjects: Fifty healthy subjects from both genders, their age ranged from 20 to 40 years old. All subjects had body mass index between 18.5 and $24.9 \mathrm{Kg} / \mathrm{m} 2$.

Method: Electromyography was used for measuring ulnar nerve conduction velocity across elbow joint at different angles $\left(0^{\circ}\right.$ extension, $45^{\circ}, 90^{\circ}$ and $120^{\circ}$ flexion) with different forearm positions (supination and pronation).

Result: Multivariate Analysis of Variance revealed that there was a statistical significant difference in mean values of ulnar nerve conduction velocity at different angles of elbow flexion with forearm supination and pronation $(\mathrm{P}=0.001)$. There was a statistical significant difference in mean values of ulnar nerve conduction velocity between forearm pronation and supination at the different angles of elbow flexion $(\mathrm{P}=0.001)$.

Conclusion: Usage of mobile hand held devices with forearm pronated and flexed elbow can decrease the motor conduction velocity of ulnar nerve more than other positions. As well as the best position for elbow joint during using mobile hand held devices is $0^{\circ}-45^{\circ}$ elbow flexion with elbow supinated.

Keywords: Ulnar nerve conduction velocity, elbow joint angles, forearm positions, mobile hand-held users.
\end{abstract}

\section{Introduction}

Forearm pronation seems crucial for ulnar nerve compression, as even with the elbow extended and lying flat on a supportive surface, pronation greatly increases the pressure on the ulnar nerve in the retroepicondylar groove, resulting in reversible nerve conduction abnormalities (4).

During elbow flexion, the ulnar nerve is stretched 4.5 to $8 \mathrm{~mm}$ since it lies posterior to the axis of motion of the elbow and the cubital tunnel cross-sectional area narrows by up to $55 \%$ as intraneural pressures increase up to 20 -fold.As a result, repeated and sustained elbow flexion can irritate the ulnar nerve and eventually lead to cubital tunnel syndrome (5).

Cubital tunnel syndrome is entrapment of ulnar nerve in the cubital tunnel. Occupations at risk for cubital tunnel syndrome involve repetitive elbow flexion and 
extension, holding tools in constant positions and using vibrating tools (6). Patients presents with intermittent parasthesia, numbness and tingling in the small finger and ulnar half of the ring finger. As the disease progress, the symptoms become constant and patients may complain of elbow pain around cubital tunnel, nonspecific complains of hand clumsiness or weakness and atrophy of the intrinsic hand muscles innervated by the ulnar nerve (7).

Technologies may modify not only life culture but also postural habits and behavior. Mobile smart technologies like tablet-pcs, smartphones, smartwatches and different variants of smart glasses, are on the rise in everybody's life (8). The mobile phone gave the opportunity to broaden human relationships and time spent on phonecalls drastically increased in the last decades. This dramatically increased the time with flexed elbow in a prolonged phone posture, when a call is ongoing (unless headphone or Bluetooth earphone are used), in order to hold the device close to the ear and mouth, for listening and speaking, respectively. Even when typing on the mobile devices, $52 \%$ of people keep the elbow flexed at less than $90^{\circ}(9)$.

Nerve conduction velocity "NCV" tests are used to determine the velocity of the electrical signals moving along a specific peripheral nerve. The use of NCV tests permit physicians to distinguish between an injury that aroused in the myelin sheaths or an injury in the nerve axons (10). It relies on the fiber diameter, demyelination degree and internodal distance. Motor nerve conduction studies require stimulation of a peripheral nerve while using a recording from a muscle innervated by the nerve. Sensory nerve conduction studies are performed by stimulating a mixed nerve while recording from a mixed or cutaneous nerve (11).

The purpose of this research was to study correlation between forearm positions across elbow joint and ulnar nerve conduction velocity among mobile-hand held devices users.

Determining the changes in motor nerve conduction velocity (NCV) of ulnar nerve at elbow area in different angles of elbow flexion with different forearm positions is very important. So, it is essential to study a valid and applicable foundation of scientific evidence that can be used to make solid decisions about the correlation between forearm positions across elbow joint and ulnar nerve motor conduction studies in mobile hand held device users (12).

\section{Design of study}

One shot case study.

\section{Participants and Methods}

\subsection{Participants}

The study was conducted on one group of healthy participants according to general health questionnaire that was filled out by them before the commencement of this study. Fifty mobile hand-held device users from both genders were recruited in this study. Their age was ranged from 20-40 years old. All participants had body mass index (BMI) between 18.5 and $24.9 \mathrm{Kg} / \mathrm{m} 2$. Participants were evaluated using NCV for measuring the motor conduction velocity of the ulnar nerve across elbow at different angles $\left(0^{\circ}\right.$ elbow extension, $45^{\circ}, 90^{\circ}$ and $120^{\circ}$ elbow flexion) with different forearm positions (supination and pronation).

The exclusion criteria were as follows: Diabetic patients, smokers, patients with cervical dysfunction, patients with Thoracic outlet syndrome, pregnant women, upper limb injuries or fractures, all types of peripheral neuropathy and renal failure patients.

\subsection{Instrumentation}

2.2.1. Elbow stabilizer with Universal goniometer for elbow position measurement $\left(0^{\circ}\right.$ elbow extension, $45^{\circ}, 90^{\circ}$ and $120^{\circ}$ of elbow flexion) with supination and pronation.

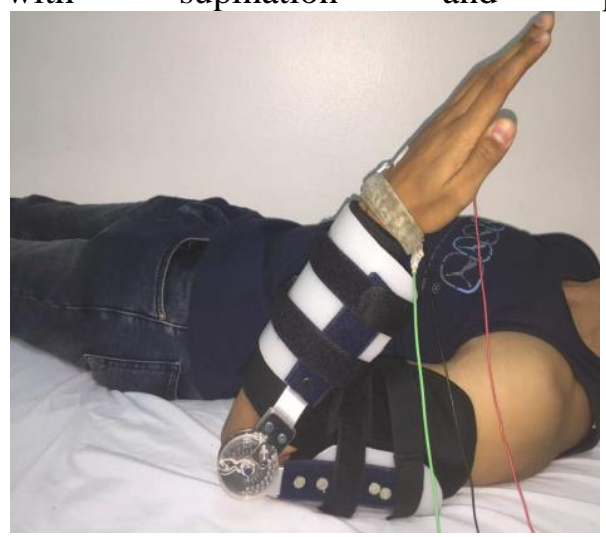

2.2.2. The Neuropack S1 MEB-9004 NIHON KODEN, JAPAN was utilizes as an objective evaluation of the motor conduction velocity. It is designed to be a compact, self-contained unit. It is composed of a main unit featuring high performance 2-channel amplifiers, a junction box with isolation amplifiers and an articulated arm.

2.2.3. Tape measurement for measuring the distance between proximal and distal stimulation sites of electrodes.

\subsection{Procedures}

2.3.1. Preparation of participants:

Subjects participated in the current study after the approval of ethical committee of Faculty of Physical Therapy, Cairo University, Egypt. Each participant signed a consent form before the beginning of the study.

The EMG machine and the protocol of the ulnar nerve motor conduction velocity measurement was explained for each participant, briefly participants were asked to remove any metallic objects to avoid any interference. For measurement of conduction velocity, the examined upper limb was uncovered. The skins of the participants at the areas of recording and stimulating electrodes were cleaned by alcohol. Weight and height of every participant were measured prior to nerve conduction study in order to exclude any obese participants, body mass index was retrieved from the following equation: 


Body mass index $(\mathrm{BMI})=\frac{\text { Weight }(\mathrm{kg})}{\text { Height }(\mathrm{m})^{2}}$

2.3.2. Measurements of ulnar nerve MCV:

The participant was in comfortable position (supine position) with forearm supported on the plinth during each measurement. Placement of recording (pick up) electrodes for ulnar nerve MCV (surface electrodes): The active surface electrode (-) black colour, was placed on the bulk of abductor digitiminimi muscle found on the ulnar surface of the hypothenar eminence, halfway between the level of the pisiform bone and the $5^{\text {th }}$ metacarpophalangeal joint. Reference or interference electrode: (+) red one was placed just distal to $5^{\text {th }}$ metacarpophalangeal joint. Ground electrode: Green one: was placed between the pick up (recording) electrodes and stimulating electrode around the wrist. All the above electrodes were fixed with paper tape to prevent the over flow except the ground electrode which is strapped.

The ulnar nerve was stimulated at four sites: At the wrist just above the wrist joint on the ulnar border, below the elbow joint below the medial epicondyle, above elbow behind and above the medial epicondyle and at axilla.

Measurement at the above elbow level was done in four different elbow positions at $0^{\circ}$ elbow extension, $45^{\circ}, 90^{\circ}$ and $120^{\circ}$ elbow flexion positions. Each degree was done in two times: forearm supination and forearm pronation. Joint was held in the assumed position using elbow stabilizer with universal geniometer. Distance between distal and proximal stimulation was measured by the tape to calculate conduction velocity of the ulnar nerve using the following formula (13).

Distance (cm)

Conduction velocity $=$

(Meter/second)

Proximal latency-Distal latency

\section{Data Analysis}

Multivariate Analysis of Variance was performed to compare between effects for all measured variables. Pearson correlation coefficient was conducted to find out the relationship between the ulnar nerve conduction velocity among different elbow flexion angles with different forearm positions. Statistical package for the social sciences computer program (version 20 for Windows; SPSS Inc., Chicago, Illinois, USA) was used for data analysis. P less than or equal to 0.05 was considered significant.

\section{Results}

Data were collected from the fifty participants consisted of $25 \mathrm{males}$ and $25 \mathrm{females,}$ their mean age, weight, height and BMI were $26.6 \pm 3.4$ years, $64.9 \pm 8.8 \mathrm{~kg}$, $167.75 \pm 9.5 \mathrm{~cm}$ and $23 \pm 1.27 \mathrm{~kg} / \mathrm{m}^{2}$ respectively.

Comparison of ulnar nerve conduction velocities among elbow flexion angles and forearm positions was done as shown in (table 1). With forearm supination there was statistical significant difference in mean values of ulnar nerve conduction velocities among different angles of elbow flexion $\left(0^{\circ}\right.$ extension, $45^{\circ}, 90^{\circ}, 120^{\circ}$ flexion $)$ $(\mathrm{P}=0.001)$. With forearm pronation there was statistical significant difference in mean values of ulnar nerve conduction velocities at different angles of elbow flexion $\left(0^{\circ}\right.$ extension, $45^{\circ}, 90^{\circ}, 120^{\circ}$ flexion) $(\mathrm{P}=0.001)$. At different elbow flexion angles there was statistical significant difference in mean values of ulnar nerve conduction velocities between forearm supination and pronation at the different angles of elbow flexion $(\mathrm{P}<0.05)$.

Table (1): Difference of mean value of ulnar nerve conduction velocity between Supination and pronation positions:

\begin{tabular}{|c|c|c|c|c|}
\hline $\begin{array}{c}\text { Angles } \\
\text { of elbow } \\
\text { flexion }\end{array}$ & $\begin{array}{c}\text { Supination } \\
\text { Mean } \pm \text { SD }\end{array}$ & $\begin{array}{c}\text { Pronation } \\
\text { Mean } \pm S D\end{array}$ & $\begin{array}{c}\text { f- } \\
\text { value }\end{array}$ & p-value \\
\hline $\mathbf{0}^{\mathbf{0}}$ & $67 \pm 6.9 \mathrm{~m} / \mathrm{s}$ & $62.5 \pm 7.5 \mathrm{~m} / \mathrm{s}$ & 10.97 & $0.001^{*}$ \\
\hline $\mathbf{4 5}^{\mathbf{0}}$ & $63.2 \pm 6.7 \mathrm{~m} / \mathrm{s}$ & $59.6 \pm 7.3 \mathrm{~m} / \mathrm{s}$ & 7.01 & $0.008^{*}$ \\
\hline $\mathbf{9 0}^{\mathbf{0}}$ & $59.6 \pm 6.6 \mathrm{~m} / \mathrm{s}$ & $56.6 \pm 6.5 \mathrm{~m} / \mathrm{s}$ & 5.03 & $0.025^{*}$ \\
\hline $\mathbf{1 2 0}^{\mathbf{0}}$ & $57.1 \pm 6 \mathrm{~m} / \mathrm{s}$ & $53.3 \pm 6.1 \mathrm{~m} / \mathrm{s}$ & 7.97 & $0.005^{*}$ \\
\hline f-value & 20.2 & 17.19 & \multicolumn{2}{|l}{} \\
\cline { 1 - 3 } p-value & $0.001^{*}$ & $0.001^{*}$ & & \\
\cline { 1 - 3 } & & &
\end{tabular}

P- value: Probability value. *: Significant.

Post-hoc test was conducted between ulnar nerve conduction velocities at different elbow flexion angles. As observed in table (2). Least Significant Difference test used to find the statistical mean difference between the mean values of ulnar nerve conduction velocity at different elbow flexion angles from supination and pronation. From supination there were significant differences between ulnar nerve conduction velocities at $0^{\circ}$ versus $90^{\circ}$, at $0^{\circ}$ versus $120^{\circ}$ and at $45^{\circ}$ versus $120^{\circ}$ elbow flexion $(\mathrm{P}=0.001)$. While there were no significant differences between ulnar nerve conduction velocities at $0^{\circ}$ versus $45^{\circ}, 45^{\circ}$ versus $90^{\circ}$ and at $90^{\circ}$ versus $120^{\circ}$ elbow flexion $(\mathrm{P}>0.05)$. From pronation there were significant differences between ulnar nerve conduction velocities at $0^{\circ}$ versus $90^{\circ}$, at $0^{\circ}$ versus $120^{\circ}$ and at $45^{\circ}$ versus $120^{\circ}$ elbow flexion $(\mathrm{P}=0.001)$. While there were no significant differences between ulnar nerve conduction velocities at $0^{\circ}$ versus $45^{\circ}$, at $45^{\circ}$ versus $90^{\circ}$ and at $90^{\circ}$ versus $120^{\circ}$ elbow flexion $(\mathrm{P}>0.05)$.

Table (2): Post hoc test between the different elbow flexion angles from supination and pronation.

P- value: Probability value. *: Significant.

\begin{tabular}{|c|c|c|c|c|}
\hline \multirow{2}{*}{ Comparison } & \multicolumn{2}{|c|}{ Supination } & \multicolumn{2}{|c|}{ Pronation } \\
\hline & $\begin{array}{c}\text { Mean } \\
\text { difference }\end{array}$ & $\begin{array}{c}P- \\
\text { value }\end{array}$ & $\begin{array}{c}\text { Mean } \\
\text { difference }\end{array}$ & $\begin{array}{c}\text { P- } \\
\text { value }\end{array}$ \\
\hline $0^{\circ}$ versus. $45^{\circ}$ & $3.7 \mathrm{~m} / \mathrm{s}$ & 0.030 & $2.9 \mathrm{~m} / \mathrm{s}$ & 0.190 \\
\hline $0^{\circ}$ versus. $90^{\circ}$ & $7.3 \mathrm{~m} / \mathrm{s}$ & $0.001 *$ & $5.8 \mathrm{~m} / \mathrm{s}$ & $0.001 *$ \\
\hline $\mathbf{0}^{\circ}$ versus. $120^{\circ}$ & $9.85 \mathrm{~m} / \mathrm{s}$ & $0.001 *$ & $9.19 \mathrm{~m} / \mathrm{s}$ & $0.001 *$ \\
\hline $45^{\circ}$ versus. $90^{\circ}$ & $3.5 \mathrm{~m} / \mathrm{s}$ & 0.054 & $2.99 \mathrm{~m} / \mathrm{s}$ & 0.161 \\
\hline $45^{\circ}$ versus. $120^{\circ}$ & $6.05 \mathrm{~m} / \mathrm{s}$ & $0.001 *$ & $6.29 \mathrm{~m} / \mathrm{s}$ & $0.001^{*}$ \\
\hline $90^{\circ}$ versus. $\mathbf{1 2 0}^{\circ}$ & $2.5 \mathrm{~m} / \mathrm{s}$ & 0.373 & $3.3 \mathrm{~m} / \mathrm{s}$ & 0.088 \\
\hline
\end{tabular}


Correlation between ulnar nerve conduction velocity at different elbow flexion angles with forearm supination was: there was significant indirect strong correlation between ulnar nerve conduction velocities at the different elbow flexion angles with forearm supination and elbow extension. There was significant direct strong correlation between ulnar nerve conduction velocities at the different elbow flexion angles and forearm supination ( $\mathrm{p}$-value $<0.05$ ) as shown in table (3).

Table (3): Correlation between ulnar nerve conduction velocity at different elbow flexion angles with forearm supination.

\begin{tabular}{|c|c|c|c|c|c|}
\hline & & & \multicolumn{3}{|c|}{ Forearm Supination } \\
\hline \multicolumn{3}{|c|}{ Elbow flexion } & $45^{\circ}$ & $90^{\circ}$ & $120^{\circ}$ \\
\hline \multirow{4}{*}{ 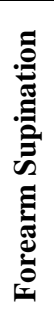 } & $\mathbf{0}^{\circ}$ & $\begin{array}{c}r \\
\text { P-value }\end{array}$ & $\begin{array}{c}-0.939 \\
0.001 *\end{array}$ & $\begin{array}{c}-0.864 \\
0.001 *\end{array}$ & $\begin{array}{l}-0.829 \\
0.001 *\end{array}$ \\
\hline & $45^{\circ}$ & $\begin{array}{c}\mathrm{r} \\
\text { P-value }\end{array}$ & 1 & $\begin{array}{c}0.932 \\
0.001 *\end{array}$ & $\begin{array}{c}0.904 \\
0.001 *\end{array}$ \\
\hline & $90^{\circ}$ & $\begin{array}{c}\mathrm{r} \\
\text { P-value }\end{array}$ & $\begin{array}{c}0.932 \\
0.001 *\end{array}$ & 1 & $\begin{array}{c}0.969 \\
0.001 *\end{array}$ \\
\hline & $120^{\circ}$ & $\begin{array}{c}\mathrm{r} \\
\text { P-value }\end{array}$ & $\begin{array}{c}0.904 \\
0.001 *\end{array}$ & $\begin{array}{c}0.969 \\
0.001 *\end{array}$ & 1 \\
\hline
\end{tabular}

r: Pearson correlation coefficient P- value: Probability value

\section{*: Significant}

Correlation between ulnar nerve conduction velocities at different elbow flexion angles with forearm pronation was: there was significant direct strong correlation between ulnar nerve conduction velocity at the different elbow flexion angles with forearm pronation (p-value <0.05) as shown in table (4).

Table (4): Correlation between ulnar nerve conduction velocities at different elbow flexion angles with forearm pronation.

\begin{tabular}{|c|c|c|c|c|c|c|}
\hline \multirow{2}{*}{\multicolumn{3}{|c|}{ Elbow flexion }} & \multicolumn{4}{|c|}{ Pronation } \\
\hline & & & \multirow{2}{*}{$\begin{array}{r}\mathbf{0}^{\mathbf{0}} \\
1 \\
\end{array}$} & \multirow{2}{*}{$\begin{array}{c}\mathbf{4 5}^{\mathbf{0}} \\
0.968 \\
0.001^{*}\end{array}$} & \multirow{2}{*}{$\begin{array}{c}\mathbf{9 0}{ }^{\mathbf{0}} \\
0.919 \\
0.001 * \\
\end{array}$} & \multirow{2}{*}{$\begin{array}{c}\mathbf{1 2 0}^{\mathbf{0}} \\
0.808 \\
0.001^{*} \\
\end{array}$} \\
\hline \multirow{3}{*}{ 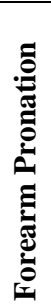 } & $0^{\circ}$ & $\begin{array}{c}\mathrm{r} \\
\text { P-value }\end{array}$ & & & & \\
\hline & $45^{\circ}$ & $\begin{array}{c}\mathrm{r} \\
\text { P-value }\end{array}$ & $\begin{array}{c}0.968 \\
0.001 *\end{array}$ & 1 & $\begin{array}{c}0.923 \\
0.001^{*}\end{array}$ & $\begin{array}{c}0.845 \\
0.001^{*}\end{array}$ \\
\hline & $90^{\circ}$ & $\begin{array}{c}\mathrm{r} \\
\text { P-value }\end{array}$ & $\begin{array}{c}0.919 \\
0.001 *\end{array}$ & $\begin{array}{c}0.923 \\
0.001 *\end{array}$ & 1 & $\begin{array}{c}0.898 \\
0.001^{*}\end{array}$ \\
\hline
\end{tabular}

P- value: Probability value. *: Significant

Correlation between ulnar nerve conduction velocity at different elbow flexion angles with forearm positions was: there was significant direct strong correlation between ulnar nerve conduction velocities at the different elbow flexion angles with forearm pronation (p-value $<0.05$ ) as shown in table (5).

Table (5): Correlation between ulnar nerve conduction velocity at different elbow flexion angles with forearm supination and pronation

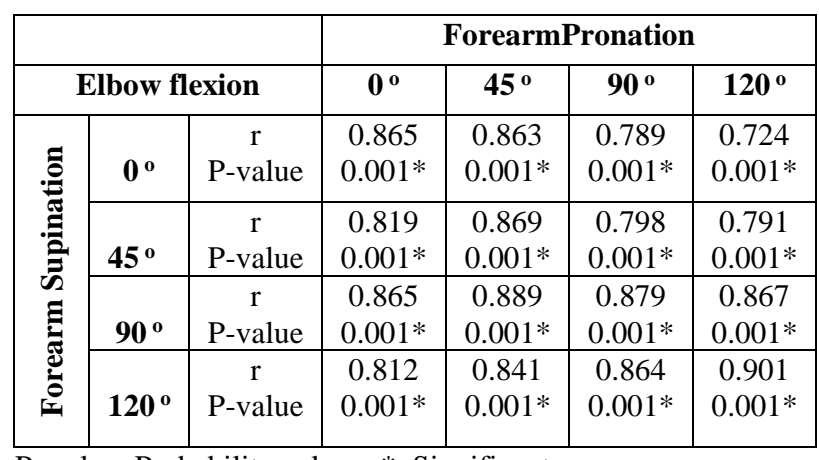

P- value: Probability value. *: Significant

\section{Discussion}

In this study, the result of the ulnar nerve conduction velocity was examined from two forearm positions (supination and pronation) at four different elbow positions $\left(0^{\circ}\right.$ extension, $45^{\circ}$ flexion, $90^{\circ}$ flexion and $120^{\circ}$ flexion). Results revealed that forearm supination showed higher nerve conduction velocity than forearm pronation and full extension showed higher nerve conduction velocity than other positions. As well as a significant reduction of nerve conduction velocity of ulnar nerve at $45^{\circ}$ of elbow flexion compared with $90^{\circ}$ of elbow flexion from forearm supination and pronation. There was a significant reduction of nerve conduction velocity of ulnar nerve at $45^{\circ}$ of elbow flexion compared with $120^{\circ}$ of elbow flexion from forearm supination and pronation respectively. This indicated that the higher nerve conduction velocity at $45^{\circ}$ of elbow flexion with supinated forearm.

Ulnar neuropathy at the elbow is the second most frequent peripheral nerve entrapment neuropathy in the upper extremity (14). Symptoms arise from compression, traction, and friction of the ulnar nerve, with medial elbow pain, parasthesia, and numbness in the fifth and ulnar half of the fourth digit presenting as predominant clinical features (15).

Information and Communication Technologies are becoming increasingly integrated into modern daily life (16). It includes various technological devices such as cell phones, laptop computers, desktop computers and tablets. Approximately 95\% of adults in the United States own a cell phone and $73 \%$ own a computer (17). The number of mobile phone subscribers in Egypt rose on a monthly basis by $0.43 \%-95.66$ million in February, according to a National Telecommunications Regulatory Authority report issued in 2017 (18).

Extensive use of smartphones can be associated with physical health-related problems, such as pain in the wrists, elbow and neck, it also exposes hands to intense stresses that may lead to pain and musculoskeletal disorders of the hand and thumb. Given the mobile nature of smartphones, users often hold the device with a single hand, which forces only the thumb to use the keys (19). 
It was proposed that abnormal elbow mechanics that taken during using mobile hand held devices such as prolonged flexion of the elbow with forearm pronation makes users vulnerable to ulnar nerve disorders. The current study suggest that the $120^{\circ}$ elbow flexion with pronated forearm created the most deformation in ulnar nerve conduction velocity and the full extension (zero elbow flexion) with supinated forearm resulted in the least deformation on the ulnar nerve. Certain postures or positions can place increased pressure either directly or by increasing tension on the nerves at different entrapment points (20).

As this study suggested that forearm pronation created the most deformation of ulnar nerve conduction velocity compared to supinated forearm position. Our result was supported by Prielipp et al. (1999) who stated that forearm pronation seems crucial for ulnar nerve compression, as even with the elbow extended and lying flat on a supportive surface, pronation greatly increases the pressure on the ulnar nerve in the retroepicondylar groove, resulting in reversible nerve conduction abnormalities. By contrast, the weight of the supinated arm is supported by the olecranon protecting the ulnar nerve (21). So it was in agreement with results of our study that showed that there was direct strong correlation between ulnar nerve conduction velocity at different elbow flexion angles with different forearm positions.

In 2000, based on anatomical considerations, Butler proposed the substitution of forearm pronation for supination during the upper limb neurodynamic test (ULNT). He suggested that the distance from the pisiform bone to the medial elbow is greater during forearm pronation resulting in an increase of strain along the ulnar nerve. The ULNT is a neurodynamic test used to evaluate the mechanical and physiologic response of the ulnar nerve and its surrounding tissue to movement (22).

The current result which is also supported by Gugliottiet al. (2016) who conducted pilot study titled "Impact of shoulder internal rotation on ulnar nerve excursion and strain in embalmed cadavers."This study provides evidence that the substitution of shoulder internal rotation for external rotation during the ULNT provides a comparable strain along the ulnar nerve. Patients who exhibit limitation of shoulder external rotation mobility may benefit from this substitution when also presenting with signs of ulnar nerve pathodynamics (23).

The results of this study were also supported by Sattari and Emad (2008) who conducted study titled "Changes in ulnar nerve conduction velocity across different angles of elbow flexion", motor and sensory NCV of the ulnar nerve were studied in fifty able-bodied subjects (100 limbs below and across the elbow segments to determine the effect of 5 different angles of the elbow $\left(0^{\circ}, 45^{\circ}, 90^{\circ}, 110^{\circ}\right.$ and $130^{\circ}$ of the elbow flexion) on NCV changes of the ulnar nerve. At each angle, the elbow NCV were compared with below and across segments. They found that at $0^{\circ}$ of the elbow flexion, the across elbow NCV were slower than the below elbow segments and at $45^{\circ}$ there was no statistical difference between below and across elbow NCV. At each subsequent angles of the elbow flexion, there was an increment in motor and sensory conduction velocity (24).

Extreme elbow flexion is known to facilitate transient ulnar nerve damage, and prolonged elbow flexion is considered a provocative test for carpal tunnel syndrome (25). In addition to this explanation relationship between the elbow joint angles and the ulnar nerve, flexion of the elbow causes increased tensile load on the ulnar nerve as well as increasing the pressure within the cubital tunnel up to 20 times the pressure at rest (26).

The current study showed that it was supported by similar study by Samaan et al. (2018) who conducted a research to investigate the effect of prolonged smart phone use on cervical spine and hand grip strength in adolescence. This demonstrated that prolonged use of smart phone affects the ulnar nerve conduction velocity due to sustained neck flexion due to looking downward at the smart phone screen. This effect on the ulnar nerve conduction velocity occurred because the ulnar nerve is derived from the medial cord of brachial plexus and contains fibers from spinal roots $\mathrm{C} 8$ and $\mathrm{T} 1$ which were compressed by prolonged static flexion during smartphone use they concluded that prolonged use of smartphones in adolescence decrease conduction velocity of ulnar nerve (27).

Byl et al. (2002) studied the difference in strain resulting from sequential and continuous movement of the upper extremities. They found strain of the ulnar nerve to be $2 \%$ with elbow flexion of $135^{\circ}$ and shoulder abduction of $80^{\circ}$ with sequential motion (28). As expected, they observed that prolonged mobile use has been found to cause numbness, aching, or tingling in the ulnar side of the forearm. In addition, it has been reported that nerve strain is dramatically increased with non-gliding motion (29).

Previous study compared the effects of phone handling with one hand versus both hands in a group of asymptomatic women (20-22 years) (30). A pressureinduced pain was significantly more frequent in onehanded users than in two-handed users. Another study tested the hypothesis that holding a smartphone screen with two hands may lead to decreased hand pain. . Ten right-handed participants completed tasks using either one- or two-handed grip on a smartphone, confirming the suggested hypothesis (31). So results of this current study were in agreement with all of the previous studies and also explained their results. 


\section{Conclusion}

It was concluded that forearm pronation with $90^{\circ}$ to $120^{\circ}$ elbow flexion position induced the most significant decrease in ulnar nerve conduction velocity than other positions. The best position for elbow joint during using mobile hand held devices is $0^{\circ}$ and $45^{\circ}$ elbow flexion with elbow supinated, as this position was showed the most significant increase in ulnar nerve conduction velocity and so decrease the possibility of cubital tunnel syndrome.

It was recommended that the best position during using mobile hand held devices is $0^{\circ}$ and $45^{\circ}$ elbow flexion with elbow supinated.

\section{Conflict of Interests}

The authors declare no conflict of interest.

\section{References}

1. Moore KL, Dalley AF. Clinically Oriented Anatomy. 5th ed. Lippincott Williams \& Wilkins. Muscle and Nerve.2006:19: 657.

2. Dumitru D, Amato A, Zwarts M. Electro diagnostic medicine,sec. edition. Hanley and Belfus Inc. 2002 pp, 1070-86.

3. Aleksenko D, Varacallo M. StatPears. Publishing; Treasur Island (FL): Guyon Canal Syndrome May5, 2019.

4. Prielipp RC, Morell RC, Walker FO, Santos CC, Bennett J, Butterworth J. Ulnar nerve pressure: influence of arm position and relationship to somatosensory evoked potentials.Anesthesiology1999; 91:345-54.

5. Chimenti PC, Hammert WC. Ulnar Neuropathy at the Elbow. Hand clinics 2013; 29(3),435442

6. Palmer BA, Hughes TB. Cubital tunnel syndrome. The journal of hand surgery, 2010, 35(1), 135-163.

7. Trehan SK, Parziale JR, Aklman E. Cubital tunnel syndrome: diagnosis and management. Medicine and Health Rhode Island, 2012, 95(11), 349.

8. Dennerlein JT. The state of ergonomics for mobile computing technology. Work: A Journal of Prevention, Assessment and Rehabilitation. 2015; 52(2):269-77.

9. Gold JE, Driban JB, Thomas N, Chakravarty T, Channell V, Komaroff E. Postures, typing strategies, and gender differences in mobile device usage: an observational study. ApplErgon. 2012; 43: 408-10.

10. Dhavalikar M, Narkeesh A, Gupta N. Effect of Skin Temperature on Nerve Conduction Velocity and Reliability of Temperature Correction Formula in Indian
Females. Journal Exercise Science and Physiotherapy. 2009; 5(1), 24-30.

11. Gakhar M, Verma SK, Lehri A. A Comparison of Nerve Conduction Properties in Male and Female of 20 to 30 Years of Age Group. Journal of Exercise Science and Physiotherapy. 2014; 10(1): 16-20.

12. Sattari S, Emad MR. Changes in ulnar nerve conduction velocity across different angles of elbow flexion. Iranian Red Crescent Medical Journal, 2008 (1), 12-15.

13. Oh SJ, Meyer RD. Entrapment neuropathies of the tibialnerve. Neurologic Clinics; 1991, 17(3):593-615.

14. Babusiaux D, Laulan J, Bouilleau L, et al. Contribution of static and dynamic ultrasound in cubital tunnel syndrome. OrthopTraumatolSurgRes .2014;100 (4Suppl):209-212.

15. Zhong W, Zhang W, Zheng X, Li S, Shi J. Comparative study of different surgical transposition methods for ulnar nerve entrapment at the elbow. J Int Med Res. 2011; 39(5):1766-1772.

16. Ciccarelli M, Straker L, Mathiassen SE, Pollock C. Posture variation among office workers when using different information and communication technologies at work and away. 2014; 57(11), 1678-1686.

17. Pew Research Center. Mobile fact sheet. Retrieved from http://www.pewinternet. org/factsheet/ mobile 2019.

18. Soliman Elserty, N, Ahmed Helmy N, Mohmed Mounir K. Smartphone addiction and its relation to musculoskeletal pain in Egyptian physical therapy students. European Journal of Physiotherapy, 2018; 10; 1-9.

19. Trudeaun MB, Young JG, Jindrich DL, Dennerlein JT. Thumb motor performance varies with thumb and wrist posture during single-handed mobile phone use. J Biomech. 2012; 45 : 2349-2354.

20. Andersen $\mathrm{JH}, \mathrm{Pb}$, Fuglsang-Frederiksen $\mathrm{AC}$, Johnson Bc, Wulff Svendsen SA. Computer use and ulnar neuropathy: results from a caserefernt study. Work. 2012; 41, 2434-2437.

21. Werner CO, Ohlin P, Elmqvist D. Pressures recorded in ulnar neuropathy. Acta Orthop Scan. 1985; 56:404-406.

22. Butler DS. The Sensitive Nervous System. Adelaide, Australia: Noigroup Publications 2000.

23. Gugliotti M, Futterman B, Ahrens T, Block D, Brown L, Dagro M, Lyon A. Impact of shoulder internal rotation on ulnar nerve excursion and strain in embalmed cadavers. A pilot study. 
Journal of Manual \& Manipulative Therapy. 2016; 24(2), 111-116.

24. Sattari S, Emad MR. Changes in ulnar nerve conduction velocity across different angles of elbow flexion. Iranian Red Crescent Medical Journal. 2008; (1), 12-15.

25. Ochi K, Horiuchi Y, Tanabe A, Morita K, Takeda K, Ninomiya K. Comparison of shoulder internal rotation test with the elbow flexion test in the diagnosis of cubital tunnel syndrome. J Hand Surg Am. 2011; 36:782-7.

26. Darowish M, Lawton J, Evans P. What is cell phone elbow, and what should we tell our patients? Cleve Clin J Med. 2009; 76:306-308.

27. Samaan M, Elnegmy E, Elnahhas A, Hendawy A. Effect of prolonged smart phone use on cervical spine and hand grip strength inadolescenc International Journal of Multidisciplinar Research and Development 5 (9); September:2018;49-5.

28. Byl C, Puttlitz C, Byl N, Lotz J, Topp K. Strain in the median and ulnar nerves during upperextremity positioning. J Hand SurgAm. 2002; 27(6):1032-40.

29. Mahan MA, Kenneth M Vaz, Weingarten D, Brown JM, Shah SB. Altered Ulnar Nerve Kinematic Behavior in Cadaver Model of Entrapment. Neurosurgery. 2015; 76:591-9.

30. Lee M, Hong Y, Lee S. The effects of smartphone use on upper extremity muscle activity and pain threshold. J PhysTherSci. 2015; 27(6):1743-174541.

31. Trudeau MB, Asakawa DS, Jindrich DL, Dennerlein JT. Two hand grips on a mobile phone afford greater thumb motor performance, decreased variability, and a more extended thumb posture than a one-handed grip. Appl Ergon. 2016; 52:24-28. 